\title{
Toward a Future-Ready Talent Framework for Co-operative and Work-Integrated Learning
}

\author{
Norah McRae, Dana Church, Jennifer Woodside, David Drewery, Anne Fannon, \\ Judene Pretti \\ Co-operative and Experiential Education, University of Waterloo, Canada
}

\begin{abstract}
Co-operative education (co-op) and work-integrated learning (WIL) are powerful means to prepare post-secondary students for the VUCA world: a world that is volatile, uncertain, complex, and ambiguous. Co-op and WIL programs expose students to the workplace which, among other things, allows students to learn about the contexts and challenges facing their employers. This contributes to the development of an "adaptive resilience" that is so crucial for coping with VUCA and the future of work and learning. Still, existing co-op and WIL programs can do more. We developed a Future-Ready Talent Framework that provides educators with explicit learning outcomes, gives students clear expectations, and equips organizations with a common language with which to interact with post-secondary institutions, educators, and students. Our Framework is comprised of four different skill sets: Expand Expertise, Develop Self, Build Relationships, and Design \& Deliver Solutions. Each of the four skill sets includes three distinct skills. Although it is a work in progress, our Framework can serve as the basis for improved curriculum, communication, and evaluation, and can serve as a tool for students to develop the confidence and know-how to face the future of work and learning.
\end{abstract}

Keywords: talent; skills; co-operative education; work-integrated learning; framework; VUCA. 


\section{Introduction}

We live on a planet rife with significant present and future challenges. These include climate change, globalization, technological advancements and disruption, shifting economic and political landscapes, aging populations, and social and economic divides. These conditions have created what can be called a "VUCA" world: Volatile, Uncertain, Complex, and Ambiguous (Ajith, 2015).

VUCA has a direct effect on the future of work and learning. Workplaces are shifting to the "Fourth Industrial Revolution," or "Industry 4.0" (Schwab, 2017) which is characterized by the implementation of artificial intelligence, automation, and robots. As a result, jobs, roles, and recruitment strategies are being redefined. Employees now more than ever need frequent upskilling or re-skilling, placing an increasing emphasis on lifelong learning. There is also a proliferation of contract work (i.e., the "gig economy") and a decline in standard careers (Royal Bank of Canada, 2018); people cannot expect to remain in a position or with an organization for the total of their working life. Indeed, successful workers are workers who have the skills to cope with VUCA.

Co-operative education (co-op) and work-integrated learning (WIL) programs offered by post-secondary institutions are powerful means to prepare students for the VUCA world. In Canada, WIL is defined as:

a model and process of curricular experiential education which formally and intentionally integrates a student's academic studies within a workplace or practice setting. WIL experiences include an engaged partnership of at least: an academic institution, a host organization, and a student. WIL can occur at the course or program level and includes the development of learning outcomes related to employability, personal agency, and lifelong learning. (Co-operative Education and Work-Integrated Learning Canada [CEWIL], 2019, p. 1)

CEWIL defines nine types of WIL. Co-op is one form of WIL in which students alternate between academic terms and paid work terms. Sometimes students complete several co-op work terms back-to-back. In all cases, the work terms take place in a workplace setting that is related to the student's field of study or career aspirations (CEWIL, 2019). The number of work terms a student must complete varies by program, but "the time spent in work terms must be at least $30 \%$ of the time spent in academic study for programs over 2 years in length and 25\% of the time for programs 2 years and shorter in length” (CEWIL, 2019).

Our institution hosts over 120 accredited co-op programs across campus, with over 20,000 undergraduate students participating annually over 3 semesters, and a network of 6,900 employers (University of Waterloo, 2019). Our co-op and WIL programs incorporate the elements of quality WIL programming (McRae \& Johnston, 2016; McRae et al., 2018) by 
exposing students to multiple workplace experiences; providing pedagogical supports before, during, and after each experience; requiring feedback from their employers in the form of a workplace assessment; and requiring the completion of reflective exercises as part of their work term report. Through this process students learn about the contexts and challenges facing their employers, which contributes to the development of an "adaptive resilience" that is so crucial for coping with VUCA and the future of work and learning.

Still, there is potential to further leverage our institution's co-op and WIL opportunities to more directly address VUCA and make our students more future-ready. For one, we can strengthen the integration between and among students' workplace experiences and their degree programs. We can also help students make further sense of these experiences, while highlighting their future-ready capabilities and the role that WIL experiences have played in developing these. Doing so will give them the confidence and know-how to compete for and create new types of jobs and roles, the habits of mind for lifelong learning, and provide them the clarity of purpose in their academic, personal, and professional lives required to apply their talents to the world's needs.

The challenge of effecting such changes in a higher education setting is that it requires not only new educational programming and resources, but also a clear vision. We propose that a Future-Ready Talent Framework will provide just that. It will also provide educators with explicit learning outcomes, give students clear expectations, and equip organizations with a common language with which to interact with post-secondary institutions, educators, and students. As such, the framework will serve as the basis for improved curriculum, communication, and evaluation. This paper presents the work that has been completed on our framework thus far.

\section{Methodology}

A search of the academic and grey literature was conducted for existing skills and competency frameworks that focused on employment and/or post-secondary education. A final sample of 19 frameworks was identified. A mapping exercise was undertaken whereby the skills and competencies included in all 19 frameworks were listed, overlap was analyzed, and a synthesized framework was created. Expert stakeholders in co-op, career development, and WIL at our institution provided feedback on the new framework. This feedback was incorporated to produce a refined framework.

\section{Results}

A list of 57 skills was obtained from the 19 frameworks included in our analysis. Of the 57 skills, 15 of them occurred in at least half of the 19 frameworks. This list of 15 skills was 
reduced to 12 after combining some of the skills (for example, the skills of reading and writing were subsumed under the skill of communication).

The 12 skills that are included in our framework can be grouped into four different "skill sets," as shown in Figure 1: Expand Expertise, Develop Self, Build Relationships, and Design \& Deliver Solutions. When students are equipped with these skill sets, they have what we term "Future-Ready Talent." This refers to talent that makes students qualified for job opportunities that will be in demand in the future.

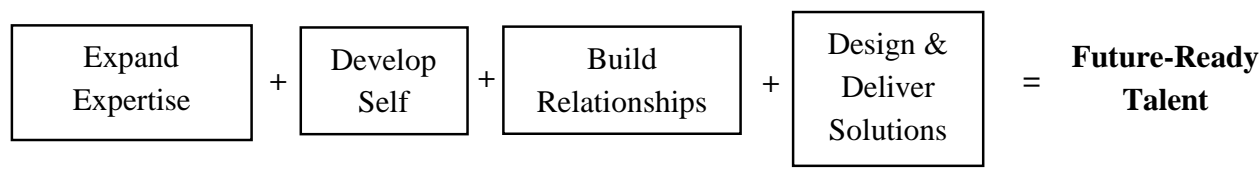

Figure 1. Skill sets that lead to future-ready graduates.

Each skill set depicted in Figure 1 contains three skills, which are listed in Table 1 and outlined below.

Table 1. The Waterloo Future-Ready Talent Framework

\begin{tabular}{cccc}
$\begin{array}{c}\text { Expand } \\
\text { Expertise }\end{array}$ & Develop Self & $\begin{array}{c}\text { Build } \\
\text { Relationships }\end{array}$ & $\begin{array}{c}\text { Design \& } \\
\text { Deliver } \\
\text { Solutions }\end{array}$ \\
\hline $\begin{array}{c}\text { information \& } \\
\text { data literacy }\end{array}$ & self-assessment & communication & $\begin{array}{c}\text { critical } \\
\text { thinking }\end{array}$ \\
technological & self-management & collaboration & $\begin{array}{c}\text { innovation } \\
\text { mindset }\end{array}$ \\
$\begin{array}{c}\text { context specific } \\
\text { knowledge \& }\end{array}$ & continuous & cross-cultural & implementation \\
skills & learning \& & agility & \\
& career & & \\
\hline
\end{tabular}

\subsection{Expand Expertise}

Expand Expertise refers to field-specific skills gained from a student's academic program as well as workplace and extra-curricular experiences. These skills might also be acquired through a student's self-directed learning (e.g., voluntary enrolment in online skills courses). The inclusion of this skill set in our framework is consistent with previous research (Pretti \& 
Drewery, 2018) which found that employers are looking for students who have, among other things, technical skills and previous work experience.

In our framework, information \& data literacy pertains to the ability to critically identify and assess the quality and relevance of both quantitative and qualitative data; to organize and synthesize data from multiple sources into meaningful information; and translate information for various audiences., Technological literacy refers to embracing the use of new technologies; evaluating the strengths and limitations of possible technologies; applying technology to increase efficiency and achieve better results; and advocating for innovative technologies, including teaching others. Finally, context-specific knowledge \& skills involves understanding and acknowledging the limits of one's own knowledge, skills, and abilities; developing knowledge and skills relevant to one's specific work situation; and demonstrating curiosity for the workplace context.

\subsection{Develop Self}

The ability to develop one's self is essential to success. Successful workers are those who continually develop and improve themselves. They have a clear sense of self (including priorities and goals), skills that help them overcome obstacles, and a tendency to improve or "up-skill” with each experience. There are three component abilities that comprise Develop Self: self-assessment, self-management, and continuous learning \& career development. Self-assessment is the ability to seek out feedback from others; reflect upon one's performance; incorporate feedback and personal reflections into performance; learn from one's mistakes; and acknowledge personal areas of weakness. Self-management requires managing and regulating one's emotions; respecting one's own and others' boundaries between work and other domains of life, and adapting to the workplace culture. Continuous learning \& career management involves setting goals to further their development; documenting growth and accomplishments; seeking experiences that allow them to test what they excel at and enjoy; approaching day-to-day challenges as opportunities to learn and grow; and exploring career opportunities actively, including through maintaining two-way professional relationships based on shared interests/goals.

Continuous learning overlaps with the concept of "lifelong learning," which involves an internalized love of learning, critical thinking about one's own learning, resilience in the face of learning challenges, and self-direction (Drewery et al., 2017). In previous research (Pretti \& Drewery, 2018), lifelong learning was one of the "talents" that employers reported they look for in candidates during the recruitment process.

\subsection{Build Relationships}

We live in a social world and we need to work with others to solve problems and to succeed in our personal endeavors. There are three components to successfully building relationships: 
communication, collaboration, and cross-cultural agility. Communication involves the ability to use clear and concise language; to listen to and ask questions of others to gain perspective; to adapt one's communication style and tone to the audience and circumstance; and to demonstrate respectful written, verbal, and non-verbal communication. Collaboration requires recognizing the value of diverse perspectives; actively listening to others, including demonstrating interest through verbal and non-verbal behaviours; taking responsibility for one's own actions; giving credit to others and noticing their ideas, strengths, and contributions; participating as an active member of the team; and doing a fair share of the team's work. Cross-cultural agility means using language that is inclusive of diverse groups; taking steps to learn about the values and norms present within the workplace; acknowledging and respecting multiple points of view within workplace settings; and adapting to the organization's cultural dynamics.

\subsection{Design \& Deliver Solutions}

Problem solving is at the heart of the workplace. In order to create solutions, one must be able to think critically. This involves seeking to understand the "big picture," root problem, or purpose for one's actions. It also includes identifying multiple possible options or solutions to the problem, applying criteria to determine the best course of action, and making evidencebased decisions and/or recommendations. An innovation mindset refers to the ability to identify important problems and areas for improvement; actively integrating ideas from across contexts; demonstrating curiosity, including asking relevant questions about important issues; exploring implications of proposed solutions; and taking measured risks. Finally, implementation means managing one's own deadlines; demonstrating a commitment to goals; identifying concrete steps necessary to complete projects; tracking progress towards defined goals; and organizing and aligning one's work plan with overarching goals. Worth noting is that an innovation mindset has been identified as uniquely human; robots or automation cannot display this skill (Aoun, 2017).

\section{Discussion}

In this study we gathered a large number of skills and competency frameworks, mapped their components, and synthesized the data into one framework. This process of comparison and selection of skills from pre-existing frameworks necessarily results in our final framework containing skills that have been identified before. Given that, it may appear at first glance that our framework offers "nothing new" in terms of what skills are required in the workplace. However, we argue that certain skills are timeless. This "timelessness" of particular skills stems from the fact that regardless of how automated the workplace becomes, people are what matter (Aoun, 2017). Communication, for example, will always be needed. Critical thinking is always in demand because computers and robots cannot solve all of our problems. 
They are incapable of human levels of creativity and divergent thinking (Aoun, 2017, Royal Bank of Canada, 2018). Other skills, such as cross-cultural agility, are more "future-focused," as they have been emphasized more recently as being necessary for success at work. For cross-cultural agility in particular, this is due to the growing trends of globalization and workers holding numerous jobs across various work cultures over the duration of their career. As another example, implementation has also been emphasized in our framework due to a labour market that is increasingly dominated by projects, contracts, and "portfolio careers." Thus, by consulting existing frameworks with an eye to the future, our resulting framework necessarily comprises a blend of both old and new.

Co-op and WIL programs provide students opportunities they might not otherwise have to develop the skills featured in the Waterloo Future-Ready Talent Framework. Workplace experiences allow students to see these skills, and to put these skills, into action. The combination of workplace experiences and the framework as a tool for reflecting upon those experiences, will allow students to "hit the ground running" as they enter the world of work.

Our framework is a work-in-progress. Next steps include validating the framework through consulting stakeholder groups, administering surveys, and using statistical methods.

There are several ways we envision the framework being used to guide WIL programming at our institution, ultimately preparing students to be successful in the VUCA world. For students, all those who participate in co-op and WIL at Waterloo will be introduced to, trained and assessed on, and encouraged to reflect on these talents. Ultimately, this will lead to an enhanced learning experience, providing students improved awareness of the skills they can develop through co-op and WIL and assisting their ability to identify, articulate and demonstrate their value vis-à-vis these future skills. For faculties, the framework can facilitate increased awareness of the role WIL plays in developing students' skills and it can guide them with data collection for program reviews and curriculum renewal. They can also use the framework as a tool to improve integration of course content with workplace contexts. For employers, the Future-Ready Talent Framework can provide clarity for crafting job descriptions and supervisory practices for co-op positions that will ensure a better fit between students and roles at their organization and student mentorship overall. Finally, at an institutional level, the framework will allow the University of Waterloo to aggregate outcomes and demonstrate impact of co-operative education and WIL, all the while engaging in a continuous improvement process.

\section{References}

Ajith, P. (2015, October-December). KESHAVA - Holistic employee selection framework in the VUCA world. SCMS Journal of Indian Management, pp. 5-18. 
Aoun, J. E. (2017). Robot-proof: Higher education in the age of artificial intelligence. Cambridge, MA: The MIT Press.

CEWIL. (2019). WIL definitions. Retrieved January 30, 2019, from https://www.cewilcanada.ca/_Library/Rebrand_CEWIL/WIL-Def-Final.pdf

Drewery, D., Nevison, C., Pretti, T. J., \& Pennaforte, A. (2017). Lifelong learning characteristics, adjustment and extra-role performance in cooperative education. Journal of Education and Work, 30(3), 299-313.

McRae, N., \& Johnston, N. (2016). The development of a proposed global work-integrated learning framework. Asia-Pacific Journal of Cooperative Education, 17(4), 337-348.

McRae, N., Pretti, T. J., \& Church, D. (2018). Work-integrated learning quality framework, AAA*. Retrieved January 30, 2019, from https://uwaterloo.ca/centre-advancement-cooperative-education/sites/ca.centre-advancement-co-operative education/files/uploads/files/wil_quality framework_-_aaa_-_for_posting.pdf

Pretti, J., \& Drewery, D. (2018). Universities: A talent pipeline for Ontario organizations? Final report. Report prepared for the Ontario Human Capital Research and Innovation Fund.

Royal Bank of Canada. (2018). Humans wanted: How Canadian youth can thrive in the age of disruption. Retrieved January 29, 2019, from www.rbc.com/humanswanted

Schwab, K. (2016). The fourth industrial revolution. New York: Crown Business.

University of Waterloo.. (2019). About co-operative education. Retrieved January 30, 2019, from https://uwaterloo.ca/co-operative-education/about-co-operative-education 